\title{
Role of Outer-membrane Proteins and Lipopolysaccharide in Conjugation between Neisseria gonorrhoeae and Neisseria cinerea
}

\author{
By CAROLINE ATTARDO GENCO† AND VIRGINIA L. CLARK* \\ Department of Microbiology and Immunology, School of Medicine and Dentistry, \\ University of Rochester, Rochester, NY 14642, USA
}

(Received 12 April 1988; revised 10 August 1988)

\begin{abstract}
Little is known concerning the mechanism involved in cell contact between the donor and recipient during conjugation in Neisseria gonorrhoeae. The formation of stable mating pairs during conjugation in Escherichia coli appears to require a specific protein as well as LPS in the outer membrane of the recipient cell. To attempt to identify the cell surface components necessary for conjugation in the neisseriae, we began a comparison of the outer membrane of Neisseria cinerea strains that can $\left(\mathrm{Con}^{+}\right)$and cannot $\left(\mathrm{Con}^{-}\right)$serve as recipients in conjugation with $\boldsymbol{N}$. gonorrhoeae. There were no differences in outer-membrane protein profiles on SDSpolyacrylamide gel electrophoresis between $\mathrm{Con}^{+}$and $\mathrm{Con}^{-}$strains that could be correlated with the ability to conjugate. However, whole outer membrane isolated from Con ${ }^{+}$strains specifically inhibited conjugation while those from $\mathrm{Con}^{-}$strains did not. Proteolytic cleavage of outermembrane proteins by trypsin, pronase or $\alpha$-chymotrypsin abolished the inhibitory effect of $\mathrm{Con}^{+}$outer membranes, suggesting that these outer membranes contained a protease-sensitive protein(s) involved in conjugation. Although periodate oxidation of Con ${ }^{+}$outer-membrane carbohydrates did not abolish the inhibitory action of these membranes, purified LPS from both $\mathrm{Con}^{+}$and $\mathrm{Con}^{-}$strains inhibited conjugation when added at low concentrations. These results suggest that conjugation requires the presence of a specific conjugal receptor that consists of both LPS and one or more outer-membrane proteins. Both $\mathrm{Con}^{+}$and $\mathrm{Con}^{-}$strains contain the necessary LPS, but only Con ${ }^{+}$strains contain the required protein(s).
\end{abstract}

\section{INTRODUCTION}

Transfer of DNA from one bacterial cell to another by conjugation requires physical contact between donor and recipient cells (deHann \& Gross, 1962). In Escherichia coli, conjugative plasmids specify sex pili (filamentous appendages composed of protein subunits: Achtman \& Skurray, 1977) that are required for the establishment of early mating contact between donor and recipient cells (Curtiss, 1969). The donor and recipient then form stable mating pairs or aggregates, through extensive wall-to-wall contacts.

The role of specific surface components on the recipient cell during conjugation by a variety of bacterial species has been widely studied. $E$. coli $\mathrm{F}^{-}$mutants that are deficient in conjugation $\left(\right.$ Con $\left.^{-}\right)$(Achtman et al., 1978; Havekes \& Hoekstra, 1976; Henning et al., 1976; Schweizer \& Henning, 1977) cannot form stable mating aggregates in liquid, but can form mating aggregates stable enough to allow DNA transfer on solid surfaces. Henning $e t$ al. (1976) have shown that the gene product of the ompA cistron is needed for cells to function efficiently as recipients with Fcarrying donor cells. The ompA gene product, OmpA protein, is believed to be necessary for stabilization of mating aggregates rather than acting as a receptor for the F pilus. LPS is also

† Present address: Sexually Transmitted Diseases Laboratory Program, Centers for Disease Control, Atlanta, GA 30333, USA. 
thought to be involved in the ability of a cell to serve as a recipient in conjugation. LPS may play a role in I-specific conjugation equivalent to that of OmpA in F-specific conjugation (Havekes $e t$ al., 1977a, 1978).

Conjugation in Neisseria gonorrhoeae is different from that of $E$. coli $\mathrm{F}$, in that a plasmidencoded pilus has not been identified, and transfer only occurs when cells are on a solid surface (Roberts \& Falkow, 1977). The gonococcal $\beta$-lactamase plasmid can be transferred by conjugation from $N$. gonorrhoeae to some, but not all, strains of Neisseria cinerea (Genco et al., 1984). Thus the host-range of the gonococcal conjugal plasmid is quite limited. Virtually nothing is known about the surface structures required in the donor or recipient in the gonococcal conjugation system. An understanding of the basis for the limited host range is of particular interest now that the TetM marker, which has been shown to be on a conjugal transposon in other genera (Franke \& Clewell, 1981), has been found inserted into the gonococcal conjugal plasmid (Morse et al., 1986).

We have used transformation to introduce a derivative of the $\beta$-lactamase plasmid into an $N$. cinerea strain that cannot accept the plasmid by conjugation, ruling out a barrier at the level of plasmid replication (Genco \& Clark, 1988). Here we describe studies designed to define the role of outer-membrane proteins and LPS in the ability of different $N$. cinerea strains to serve as recipients with $N$. gonorrhoeae as donor during conjugation.

\section{METHODS}

Strains and growth conditions. The bacterial strains used in this study are listed in Table 1. N. gonorrhoeae, $N$. cinerea and $E$. coli strains were grown as described in the preceding paper (Genco \& Clark, 1988).

Isolation of outer membranes. Outer membranes of $N$. cinerea strains were prepared from overnight cultures grown on GCK agar, as previously described for $N$.gonorrhoeae (Clark et al., 1987). Outer-membrane pellets were suspended in water, and protein content was determined by the Lowry method with bovine serum albumin as a standard.

Inhibition of conjugation. $N$. gonorrhoeae CDC67 donor cells $\left(10^{7}\right)$ were suspended in GCK broth $+100 \mu \mathrm{g}$ DNAase $\mathrm{ml}^{-1}$ and incubated for $2 \mathrm{~h}$ at $37^{\circ} \mathrm{C}$ in $5 \%(\mathrm{v} / \mathrm{v}) \mathrm{CO}_{2}$-in-air on a polycarbonate membrane (Nucleopore) with or without the addition of either sarkosyl-insoluble outer membranes or purified LPS species. $N$. cinerea recipient cells $\left(10^{8}\right.$, rifampicin resistant) were then added and incubation was continued for an additional $2 \mathrm{~h}$. Transconjugants were selected on GCK $+0.25 \mu \mathrm{g}$ penicillin and $1.0 \mu \mathrm{g}$ rifampicin $\mathrm{ml}^{-1}$. Transconjugants were confirmed by detection of $\beta$-lactamase activity with the chromogenic cephalosporin nitrocefin (Glaxo Research) (O'Callaghan et al., 1972).

Treatment of outer membranes with proteolytic enzymes or periodate. Proteolytic cleavage of sarkosyl-insoluble membranes was achieved using 50 or $100 \mu \mathrm{g}$ trypsin (Sigma), 25 or $50 \mu \mathrm{g}$ pronase (Calbiochem-Behring), and 25 or $50 \mu \mathrm{g} \alpha$-chymotrypsin (Sigma), as described by Blake et al. (1981). Each enzyme was incubated with a $100 \mu \mathrm{g}$

\section{Table 1. Bacterial strains used in this study}

\begin{tabular}{|c|c|c|c|}
\hline Organism & Strain & Relevant phenotype* & Source† \\
\hline N. gonorrhoeae & CDC67 & $\mathrm{Tra}^{+} \mathrm{Bla}^{+} \mathrm{Rif}^{\mathrm{s}}$ & CDC, Atlanta \\
\hline N. cinerea & RUN4029 & $\mathrm{Bla}^{-} \mathrm{Con}^{-} \mathrm{Rif}^{\mathrm{r}}$ & NRL 30003 \\
\hline$N$. cinerea & RUN4030 & $\mathrm{Bla}^{-} \mathrm{Con}^{+} \mathrm{Rif}^{\mathrm{r}}$ & NRL 32165 \\
\hline N. cinerea & RUN4031 & $\mathrm{Bla}^{-} \mathrm{Con}^{+} \mathrm{Rif}^{\mathrm{r}}$ & NRL 32824 \\
\hline N. cinerea & RUN4032 & $\mathrm{Bla}^{-} \mathrm{Con}^{-} \mathrm{Rif}^{\mathrm{r}}$ & NRL 33295 \\
\hline N. cinerea & RUN4033 & $\mathrm{Bla}^{-} \mathrm{Con}^{+} \mathrm{Rif}^{\mathrm{r}}$ & NRL 32828 \\
\hline E. coli & HB101 & $\mathrm{Bla}^{-} \mathrm{Con}^{+}$ & H. Boyer \\
\hline
\end{tabular}

* $\mathrm{Tra}^{+}$strains contain the gonococcal conjugal plasmid, pLE2451, and Bla ${ }^{+}$strains contain the $4.4 \mathrm{MDa} \beta$ lactamase plasmid, pFT1. Con ${ }^{-}$and $\mathrm{Con}^{+}$indicate the inability or capability, respectively, of the strain to acquire the $\beta$-lactamase plasmid by conjugation with $N$. gonorrhoeae. Rif ${ }^{s}$ and $\operatorname{Rif}^{r}$ indicate that the strain is sensitive or resistant, respectively, to $1 \mu \mathrm{g}$ rifampin $\mathrm{ml}^{-1}$.

† NRL denotes Neisseria Reference Laboratory. 
protein sample of freshly prepared outer membrane for $1 \mathrm{~h}$ at $37^{\circ} \mathrm{C}$. Samples were diluted 1:10 with $0.25 \mathrm{M}$ -

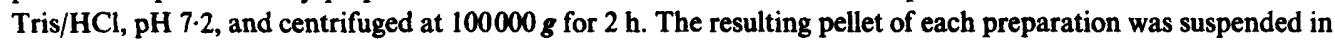
$100 \mu \mathrm{l}$ distilled water and used immediately or divided into portions and stored at $-70^{\circ} \mathrm{C}$.

Periodate oxidation of sarkosyl-insoluble membranes ( $100 \mu \mathrm{g}$ protein) was achieved by the addition of $20 \mathrm{nmol}$ sodium metaperiodate (Mallinkrodt) in 0.05 M-sodium acetate buffer, pH 5.4 (Stein \& Heath, 1979). Reactions were incubated in the dark at $4^{\circ} \mathrm{C}$ for $20 \mathrm{~h}$ and stopped by the addition of $10 \mathrm{nmol}$ glycerol.

Isolation of LPS. LPS was isolated from $N$. cinerea strains by a modification of the hot phenol/water extraction procedure of Westphal \& Jann (1965) as modified by Johnston et al. (1976). The LPS pellet was dissolved in 1.0 ml distilled water, lyophilized to a dry powder and stored at $4^{\circ} \mathrm{C}$. LPS (rough type) was isolated from $E$. coli HB101 as previously described (Palermo et al., 1987) and Salmonella minnesota LPS (smooth type) was purchased from Sigma.

$S D S$-polyacrylamide electrophoresis (SDS-PAGE). This was performed on $13 \%(\mathrm{w} / \mathrm{v})$ gels with $4 \%$ stacking gels as described by Laemmli (1970). LPS preparations were analysed by SDS-PAGE as described by Schneider $e$ al. (1984).

\section{RESULTS}

\section{Effects of trypsin treatment on conjugal transfer}

We were interested in identifying the surface structures necessary for a cell to serve as a recipient in conjugation with $N$. gonorrhoeae. Preincubation of $N$. cinerea recipient cells with trypsin $\left(250\right.$ or $500 \mu \mathrm{g}$ per $10^{9}$ cells in $\left.1 \mathrm{ml}\right)$, followed by incubation with soybean trypsin inhibitor prior to conjugation with an $N$. gonorrhoeae donor, resulted in a decrease in the frequency of conjugal transfer of the gonococcal $\beta$-lactamase plasmid (data not shown). The addition of trypsin to recipient cells decreased the number of viable cells by $45 \%$; however, the conjugation frequency was decreased by $95 \%$ and thus these results are not due simply to a decrease in the viability of recipients. Although the effects of trypsin on recipient cells may be pleiotropic, one of the major effects is the proteolytic cleavage of exposed outer-membrane proteins.

\section{$N$. cinerea outer-membrane proteins}

The decrease in the transfer of the gonococcal $\beta$-lactamase to $N$. cinerea recipient cells pretreated with trypsin suggested that an intact outer-membrane protein(s) of a $\mathrm{Con}^{+}$strain played a role in its ability to serve as a recipient with $N$. gonorrhoeae. Therefore, we began a comparison of the outer membranes from $\mathrm{Con}^{+}$and $\mathrm{Con}^{-} N$. cinerea strains by examining the outer-membrane protein composition by SDS-PAGE (Fig. 1). All five $N$. cinerea strains produced different outer-membrane protein patterns on SDS-PAGE. However, no simple correlation existed between the presence of a particular outer-membrane protein and the ability to act as a recipient in conjugation with $N$. gonorrhoeae. Silver staining of the gel also did not reveal any protein whose presence could be corrrelated with the Con ${ }^{+}$phenotype (data not shown).

\section{Inhibition of conjugation of $N$. cinerea}

When $N$. gonorrhoeae CDC67 was preincubated with outer-membrane preparations from $N$. cinerea RUN4030, 4033 and 4031 (Con ${ }^{+}$strains), and then added to $N$. cinerea RUN4030 recipient cells, inhibition of conjugation was observed (Fig. 2). While low concentrations of outer-membrane preparations from $N$. cinerea RUN4030, 4031 and 4033 strongly inhibited conjugation, much higher concentrations of outer-membrane preparations from $\mathrm{Con}^{-}$strains (RUN4029 and RUN4032) were required for inhibitory effects. Complete inhibition of conjugation was observed at $2.0 \mu \mathrm{g}$ of RUN4030, at 3.0 $\mu \mathrm{g}$ of RUN4031 and RUN4033, and at $5.0 \mu \mathrm{g}$ of RUN4029 and RUN4032 outer-membrane protein (data not shown). One microgram of outer-membrane protein is equivalent to approximately $10^{7}$ cells, which is the number of viable donor cells used in the conjugation inhibition experiments. 


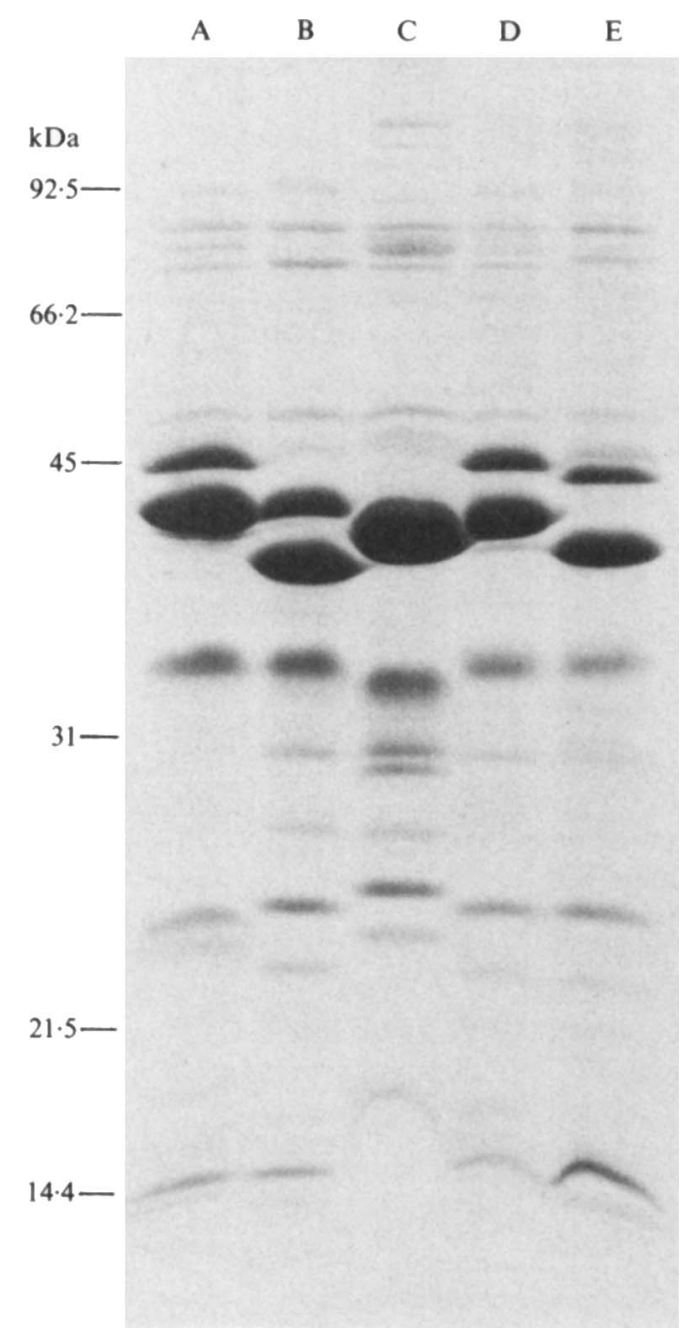

Fig. 1. SDS-PAGE of sarkosyl-insoluble outer membranes of $N$. cinerea. Electrophoresis was performed on $13 \%$ gels with $4 \%$ stacking gels (Laemmli, 1970) and the gel was stained with Coomassie blue. Strains: A, RUN4030 (Con $\left.{ }^{+}\right)$; B, RUN4031 (Con $\left.{ }^{+}\right)$; C, RUN4033 (Con $\left.{ }^{+}\right)$; D, RUN4029 (Con $\left.{ }^{-}\right)$; E, RUN4032 (Con-).

Since trypsin treatment of whole recipient cells inhibited conjugation, outer-membrane preparations from $N$. cinerea $\mathrm{Con}^{+}$organisms were treated with various proteolytic enzymes in an attempt to identify proteins important for conjugation. Outer-membrane preparations were also treated with sodium metaperiodate to degrade LPS. Periodate treatment of outer membranes from $N$. cinerea RUN4030 slightly increased the inhibitory action of these preparations when $0.75 \mu \mathrm{g}$ outer-membrane protein was added, but had no effect at $1.5 \mu \mathrm{g}$ (Table 2). Treatment of these outer-membrane preparations with each of the three proteolytic enzymes completely abolished the inhibitory action of these preparations on conjugation at both 0.75 and $1.5 \mu \mathrm{g}$ added outer-membrane protein. Trypsin treatment of outer membranes from RUN4031 and RUN4033 also decreased the inhibitory action of these preparations on conjugation, though not as completely as seen with outer membranes from RUN4030. Trypsin treatment of the Constrains, RUN4029 and RUN4032, decreased the inhibitory action of these outer-membrane 


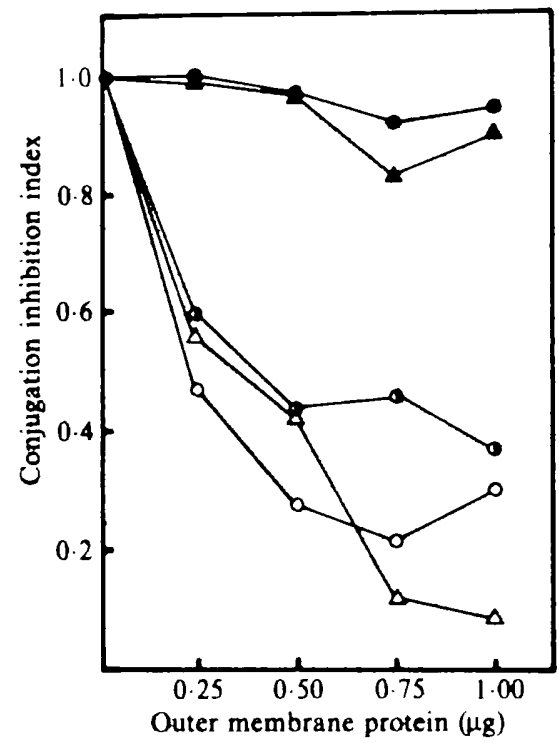

Fig. 2. Intibition of conjugation by outer-membrane preparations. N. gononhoeae CDC67 donor cells were incubated for $2 \mathrm{~h}$ with outer-membrane preparations from the five different $N$. cincrea strains. $N$. cinerea RUN4030 recipient cells were added and conjugation mixtures were incubated for an additional $2 \mathrm{~h}$. The odnjugation inhibition index was determined by dividing the conjugation frequincy for donors preincubated with outer-membrane preparations by the conjugation frequency for donors preincubated without the addition of outer membranes. The vahues are from one experiment and are ripresentative of three separate experiments. Outer membrane preparations were from: $\triangle$, RUN4032; , RUN4029; $\triangle$, RUN4033; O, RUN4031; O, RUN4030.

Table 2. Effects of treatments of $N$. cinerea outer membranes on their ability to inhibit conjugation between $N$. gonorrhoeae CDC67 donors and $N$. cinerea RUN\$030 recipents

\begin{tabular}{|c|c|c|c|}
\hline \multirow{2}{*}{$\begin{array}{l}\text { Source of } \\
\text { outer } \\
\text { membranes }\end{array}$} & \multirow[b]{2}{*}{ Treatment* } & \multicolumn{2}{|c|}{ Conjugation inhibition index } \\
\hline & & $0.75 \mu 8$ & $1.5 \mu \mathrm{g}$ \\
\hline RUN4030 & $\begin{array}{l}\text { None } \\
\text { Periodate } \\
\text { Trypsin } 50 \mu \mathrm{g} \\
\text { Trypsin } 100 \mu \mathrm{g} \\
\text { Pronase } 25 \mu \mathrm{g} \\
\text { Pronase } 50 \mu \mathrm{g} \\
\alpha \text {-Chymotrypsin } 25 \mu \mathrm{g} \\
\alpha \text {-Chymotrypsin } 50 \mu \mathrm{g}\end{array}$ & $\begin{array}{l}0-39 \\
0 \cdot 30 \\
1 \cdot 0 \\
1 \cdot 1 \\
1 \cdot 2 \\
1 \cdot 2 \\
1 \cdot 0 \\
1 \cdot 2\end{array}$ & $\begin{array}{l}0.19 \\
0.19 \\
0.80 \\
1.0 \\
0.85 \\
1.0 \\
1.2 \\
1.1\end{array}$ \\
\hline RUN4031 & $\begin{array}{l}\text { None } \\
\text { Periodate } \\
\text { Trypsin } 100 \mu \mathrm{g}\end{array}$ & $\begin{array}{l}0.36 \\
0.19 \\
0.89\end{array}$ & $\begin{array}{l}\text { ND } \\
\text { ND } \\
\text { ND }\end{array}$ \\
\hline RUN4033 & $\begin{array}{l}\text { None } \\
\text { Periodate } \\
\text { Trypsin } 100 \mu \mathrm{g}\end{array}$ & $\begin{array}{l}0.40 \\
0.38 \\
0.60\end{array}$ & $\begin{array}{l}\text { ND } \\
\text { ND } \\
\text { ND }\end{array}$ \\
\hline
\end{tabular}

ND, Not determined.

- Treatments were carried out as described in Methods.

$\uparrow$ Conjugation inhibition index was calculated as described in the legend to Fig. 2, and the values represent the mean of two independent experiments. Values of $0.75 \mu \mathrm{g}$ or $1.5 \mu \mathrm{g}$ indicate the amount of outer-membrane protein that was used in the conjugation experiments, after treatment of a $100 \mu 8$ sample with the indicated agent. 


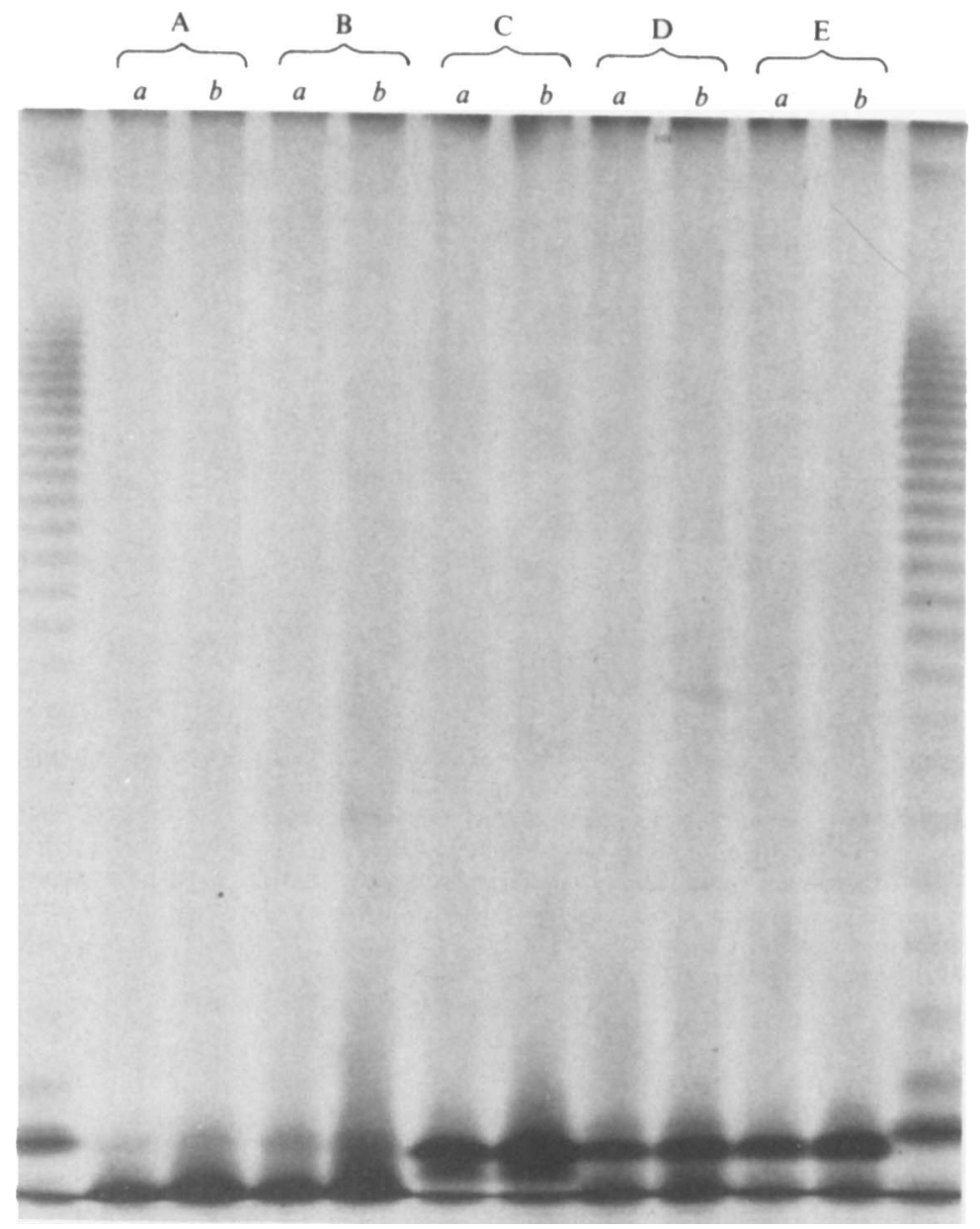

Fig. 3. SDS-PAGE of $N$. cinerea LPS preparations. Purified LPS samples from $N$. cinerea $[0.5 \mu \mathrm{g}(a)$ and $1.0 \mu \mathrm{g}(b)]$ were brought to $25 \mu \mathrm{l}$ with distilled water, $25 \mu \mathrm{l}$ of $2 \times$ LPS-SDS-PAGE sample buffer was added, and the samples were boiled for $5 \mathrm{~min}$ and subjected to SDS-PAGE on $13 \%$ separating gels (without added SDS) (Schneider et al., 1984). Gels were stained with an LPS-specific silver stain (Tsai \& Frasch, 1982). Strains: A, RUN4030 (Con $\left.{ }^{+}\right)$; B, RUN4031 (Con $\left.{ }^{+}\right)$; C, RUN4033 (Con $\left.{ }^{+}\right)$; D, RUN4029 ( $\left.\mathrm{Con}^{-}\right)$; E, RUN4032 ( $\left.\mathrm{Con}^{-}\right)$. Lanes on the far left and right are smooth-type LPS from $S$. minnesota.

preparations that was observed only at much higher concentrations (data not shown). Periodate oxidation of RUN4031 and RUN4033 outer membranes slightly increased the inhibitory effect of these outer membranes on conjugation.

\section{Inhibition of conjugation by purified LPS}

To define more closely the role of LPS in the ability of $N$. cinerea to serve as recipients in conjugation, LPS from each of the $N$. cinerea strains was purified and analysed by SDS-PAGE (Fig. 3). All five $N$. cinerea strains appeared to produce a rough-type LPS. No simple correlation could be made between the LPS banding pattern from those strains which could and could not serve as recipients in conjugation with $N$. gonorrhoeae. Two of the Con ${ }^{+}$strains, RUN4030 and RUN4031, did not produce a higher molecular mass band; however, the LPS species from Con ${ }^{+}$ RUN4033 did contain this higher molecular mass band as did Con- RUN4029 and RUN4032. 


\begin{tabular}{lcc}
\multicolumn{2}{c}{ Table 3. Inhibition of conjugation by LPS } \\
$\begin{array}{lcc}\text { Strain from which } \\
\text { LPS isolated }\end{array}$ & $\begin{array}{c}\text { LPS } \\
(\mu \mathrm{g})^{*}\end{array}$ & $\begin{array}{c}\text { Conjugation } \\
\text { inhibition index }\end{array}$ \\
N. cinerea RUN4030 & 1.0 & 0.50 \\
N. cinerea RUN4031 & 1.0 & 0.44 \\
N. cinerea RUN4033 & 1.0 & 0.64 \\
N. cinerea RUN4029 & 1.0 & 0.40 \\
N. cinerea RUN4032 & 1.0 & 0.36 \\
E. coli HB101 & 1.0 & 1.1 \\
& 10 & 1.1 \\
S. minnesota & 1.0 & 1.2 \\
& 10 & 1.0
\end{tabular}

* With $0.5 \mu \mathrm{g}$ LPS from each $N$. cinerea strain, no inhibition of conjugation was observed (index $=1.0$ ).

† Conjugation inhibition index was calculated as described in the legend to Fig. 2, and values represent the mean of two independent experiments.

These LPS species were examined for their possible role in conjugation by preincubating them with donors. These LPS/donor mixtures were then added to $N$. cinerea RUN4030 recipient cells. At $0.5 \mu \mathrm{g}$ added LPS from all $N$. cinerea strains, no inhibition of conjugation was observed. However, at $1.0 \mu \mathrm{g}$ LPS from both $\mathrm{Con}^{+}$and Con" strains, there was significant inhibition of the transfer of the $\beta$-lactamase plasmid by conjugation to $N$. cinerea recipients (Table 3 ). The addition of $5 \mu \mathrm{g}$ LPS from Con ${ }^{+}$or Con ${ }^{-}$strains resulted in an increased, but not complete, inhibition of conjugation (data not shown). No apparent difference in the inhibition exerted by LPS from Con ${ }^{+}$versus $\mathrm{Con}^{-}$strains was evident. The addition of rough $E$. coli or smooth $S$. minnesota LPS at either 1.0 or $10 \mu \mathrm{g}$ did not inhibit the transfer of the $\beta$-lactamase plasmid by conjugation to $N$. cinerea recipients, suggesting that the inhibition was specific for neisserial LPS.

\section{DISCUSSION}

The ability of outer-membrane preparations from $\mathrm{Con}^{+}$strains to specifically inhibit the transfer of the $\beta$-lactamase plasmid by conjugation suggests that $\mathrm{Con}^{+} N$. cinerea strains possess a component in the outer membrane that may be required for the formation of mating pairs, and that this component is absent or non-functional in $\mathrm{Con}^{-}$strains. Cleavage of outer-membrane preparations with proteolytic enzymes abolished the inhibition, suggesting that the component is a protein(s). Trypsin treatment of outer membranes from all five $N$. cinerea strains resulted in the cleavage of at least three and as many as five proteins, as evidenced by protein profiles on SDS-PAGE (data not shown). However, no protein was found only in the Con ${ }^{+}$strains that was cleaved by trypsin. The barrier to conjugation in $\mathrm{Con}^{-}$strains may be due to the absence of a specific trypsin-sensitive outer-membrane protein whose molecular mass may vary in the different $\mathrm{Con}^{+}$strains examined. Alternatively, the $\mathrm{Con}^{-}$strains may contain the protein but not in a functional state.

The results from the inhibition of conjugation experiments where LPS species were used are interesting in that they imply a possible role for LPS in the ability of an $N$. cinerea recipient to interact with an $\boldsymbol{N}$. gonorrhoeae donor cell during conjugation. All five $\boldsymbol{N}$. cinerea strains produced LPS species which, when preincubated with donor cells, resulted in an inhibition of the transfer of the gonococcal $\beta$-lactamase plasmid. Relatively low concentrations of LPS were needed for inhibition of conjugation, similar to the $E$. coli I system where LPS is believed to play an integral role in ability of a recipient cell to form mating pairs (Havekes et al., 1977 a, 1978). The absence of inhibition of conjugation by either $E$. coli or $S$. minnesota LPS suggests that the inhibition seen by $N$. cinerea LPS is specific. That $E$. coli HB101 LPS was not inhibitory to conjugation was somewhat surprising, since this strain can serve as a recipient in conjugation with $N$. gonorrhoeae. 
Studies in the E. coli $F$ system clearly demonstrate that the decrease in, or absence of, recipient ability can result from several different defects in the recipient cell. Havekes \& Hoekstra (1976) found that three out of four ompA mutants, selected for the loss of conjugation, retained OmpA protein in the membrane. Achtman et al. (1978) mapped 11 Con $^{-}$mutants in or near the ompA cistron and found that many of these did not synthesize detectable levels of OmpA. The remaining mutants produced normal levels of OmpA and the authors suggested that OmpA may have been non-functional in these mutants. The $\mathrm{Con}^{-}$mutants described by Achtman et al. (1978) were capable of binding F pili but incapable of forming stable mating aggregates as measured by a Coulter counter technique. The authors concluded that OmpA protein does not represent the receptor for $F$ pilus binding and that conjugation between $F$-carrying donor cells and $\mathrm{F}^{-}$recipient cells proceeds by a series of specific interactions before transfer can occur. One of these intermediate stages, that of stabilization, requires OmpA in an LPS matrix in the recipient.

In other studies (Manoil \& Rosenbusch, 1982) 62 mutants were selected for their inability to act as efficient $F$ factor recipients in conjugation. Of these, 60 were found to be altered in the amount or function of OmpA protein, while the remaining two had altered LPS. The ompA mutants were of three types: (1) those that lacked OmpA protein, (2) those that had greatly reduced levels of OmpA protein, and (3) those that had normal amounts of OmpA protein. The OmpA protein from the third type of mutants migrated differently from the normal protein in SDS-urea-PAGE.

Recently Ried \& Henning (1987) have characterized a set of $o m p A$ mutants which exhibit a conjugation-deficient phenotype but produce wild-type amounts of OmpA protein. Conjugation deficiency in these mutants appears to be caused by a single amino acid substitution in the OmpA protein, glycine-154 for aspartic acid. These authors conclude that the OmpA protein is the primary recognition site for the donor during conjugation and that only a small area of the OmpA protein is recognized.

The role of LPS in the recipient cell is not as well defined as that of OmpA. However, mutants with defects in the polysaccharide core of the LPS are poor recipients for R64drd11 and other Ilike plasmids (Havekes et al., 1977b; Manning \& Reeves, 1977). Several $\mathrm{F}^{-}$mutants have been described which have altered LPS, although the decrease in transfer may be due to changes in outer-membrane proteins and/or the interaction between these proteins and LPS (Achtman et al., 1978; Henning et al., 1976; Puspurs et al., 1983).

Duke \& Guiney (1983) studied the role of LPS structure in the recipient cell using a series of well-defined LPS mutations in $S$. minnesota. They found a decrease in transfer which was correlated with the extent of the defect in LPS structure; they believe that the progressive decrease in transfer suggests that no single component of the LPS structure acts as a specific receptor and that perhaps some general property of LPS is important in conjugation. The addition of large amounts of purified LPS to mating mixtures does not block RK2-mediated transfer and argues against a role for LPS as a receptor in the recipient for mating with RK2. However, addition of purified OmpA and LPS, but not OmpA alone, greatly decreased the number of observed F-plasmid transconjugants in E. coli K12 (Alphen et al., 1977; Schweizer \& Henning, 1977).

The differences between $\mathrm{Con}^{-}$and $\mathrm{Con}^{+} N$. cinerea may reflect differences between the interaction of LPS and a specific protein(s). If a specific protein in the recipient is required for stable mating aggregate formation, the proper configuration may be essential to its activity. One of the characteristics of $E$. coli Con $^{-}$mutants is their ability to mate on solid surfaces. The $N$. cinerea $\mathrm{Con}^{-}$strains described in our studies are not able to mate on a solid surface and, therefore, a direct comparison between $E$. coli $\mathrm{Con}^{-}$mutants may not be possible. However, the

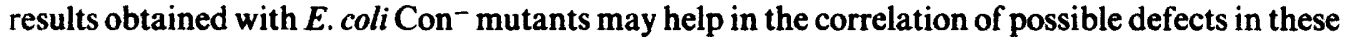
$N$. cinerea $\mathrm{Con}^{-}$strains. It is clear that most of the $E$. coli $\mathrm{Con}^{-}$mutants are defective in stable mating pair formation as a result of changes in outer-membrane proteins and/or LPS structure. In our studies, results from the inhibition of conjugation experiments demonstrate a role for outer-membrane proteins and LPS in the ability of $N$. cinerea recipient cells to mate with $N$. gonorrhoeae donor cells. 
This study was supported by US Public Health Service grant AI-11709 from the National Institute of Allergy and Infectious Diseases.

\section{REFERENCES}

ACHTMaN, M. \& SkURRAY, R. (1977). A redefinition of the mating phenomenon in bacteria. In Microbial Interactions (Receptors and Recognition), pp. 233-279. Edited by J. L. Reissig. London: Chapman \& Hall. Achtman, M., Schwuchow, S., Helmuth, R., Morelli, G. \& Manning, P. A. (1978). Cell-cell interactions in conjugating Escherichia coli Con- $^{-}$ mutants and stabilization of mating aggregates. Molecular and General Genetics 164, 171-183.

Alphen, L. van, Havekes, L. \& Lugtenberg, B. (1977). Major outer membrane protein of Escherichia coli $\mathbf{K}-12$, purification and in vitro activity on bacteriophage $\mathrm{K} 3$ and $\mathrm{F}$-plus mediated conjugation. FEBS Letters 75, 285-290.

Blake, M. S., Gotschlich, E. C. \& Swanson, J. (1981). Effects of proteolytic enzymes on the outer membrane proteins of Neisseria gonorrhoeae. Infection and Immunity 33, 211-222.

Clark, V. L., Campbell, L. E., Palermo, D. A., EVANS, T. M. \& KLIMPEL, K. W. (1987). Induction and repression of outer membrane proteins by anaerobic growth of Neisseria gonorrhoeae. Infection and Immunity 55, 1359-1364.

CURTiss, R., III (1969). Bacterial conjugation. Annual Review of Microbiology 23, 69-136.

DUKE, J. \& GUINEY, D. G., JR (1983). The role of lipopolysaccharide structure in the recipient cell during plasmid-mediated bacterial conjugation. Plasmid 9, 222-226.

Franke, A. E. \& Clewell, D. B. (1981). Evidence for a chromosome-borne resistance transposon (Tn916) in Streptococcus faecalis that is capable of "conjugal" transfer in the absence of a conjugative plasmid. Journal of Bacteriology 145, 494-502.

GenCo, C. A. \& Clark, V. L. (1988). Transfer of a gonococcal $\beta$-lactamase plasmid to conjugationdeficient Neisseria cinerea strains by transformation. Journal of General Microbiology 134, 3277-3283.

Genco, C. A., KNAPp, J. S. \& Clark, V. L. (1984). Conjugation of plasmids of Neisseria gonorrhoeae to other Neisseria species. Potential reservoirs for the beta-lactamase plasmid. Journal of Infectious Diseases 150, 397-401.

DeHaAn, P. G. \& Gross, J. D. (1962). Transfer delay and chromosome withdrawal during conjugation in Escherichia coli. Genetical Research 3, 251-272.

HAVEKes, L. M. \& HoEkstra, W. P. M. (1976). Characterization of an Escherichia coli K-12 F-Conmutant. Journal of Bacteriology 126, 593-600.

HaVekes, L. M., Hoekstra, W. \& KeMPEN, H. (1977a). Relation between F, R, R100, and R144 Escherichia coli strains in mating. Molecular and General Genetics 155, 185-189.

Havekes, L. M., Tommassen, J., Hoekstra, W. \& LUGTENBERG, B. (1977b). Isolation and characterization of Escherichia coli K-12 F-mutants defective in conjugation with an I-type donor. Journal of Bacteriology 129, 1-8.

Havekes, L. M., Hoekstra, W. \& HaCk, A. (1978). Identification of recipient cell envelope components in Escherichia coli $\mathbf{K}-12$ involved in matings with different types of plasmid donor strains. In Microbiology-1978, pp. 204-207. Edited by D. Schlessinger. Washington, DC: American Society for Microbiology.

HenNing, U., Hindennach, I. \& Haller, I. (1976). The major proteins of the Escherichia coli outer cell envelope membrane. Evidence for the structural gene of protein $\mathrm{II}^{*}$. FEBS Letters 61, 46-48.

Johnston, K. H., Holmes, K. K. \& Gotschlich, E. C. (1976). The serological classification of Neisseria gonorrhoeae. I. Isolation of the outer membrane complex responsible for serotype specificity. Journal of Experimental Medicine 143, 741-758.

LAEMMLI, U. K. (1970). Cleavage of the structural proteins during assembly of the head of bacteriophage T4. Nature, London 227, 680-685.

Manning, P. A. \& Reeves, P. (1977). Further characterization of the recipient ability of Escherichia coli $\mathrm{K}-12$ bacteriophage resistant mutants. Journal of Bacteriology 130, 540-541.

Manoll, C. \& Rosenbusch, J. B. (1982). Conjugationdeficient mutants of Escherichia coli distinguish classes of functions of the outer membrane ompA protein. Molecular and General Genetics 187, 148156.

Morse, S. A., Johnson, S. R., Biddle, J. W. \& RoBerTs, M. C. (1986). High-level tetracycline resistance in Neisseria gonorrhoeae is result of acquisition of streptococcal tet $\mathrm{M}$ determinant. Antimicrobial Agents and Chemotherapy 30, 664-670.

O'Callaghan, C. H., Morris, C. H., Kirby, S. M. \& ShINGleR, A. H. (1972). A novel method for detection for beta-lactamase by using a chromogenic cephalosporin substrate. Antimicrobial Agents and Chemotherapy 1, 283-288.

Palermo, D. A., Evans, T. M. \& Clark, V. L. (1987). Expression of a cloned lipopolysaccharide antigen from Neisseria gonorrhoeae on the surface of Escherichia coli K-12. Infection and Immunity 55, 28442849.

Puspurs, A., Medon, P., Corless, C., Hackett, J. \& ReEves, P. (1983). A class of ompA mutants of Escherichia coli K-12 affected in the interaction of OmpA protein and the core region of lipopolysaccharide. Molecular and General Genetics 189, 162165.

RIED, G. \& HeNnING, U. (1987). A unique amino acid substitution in the outer membrane protein ompA causes conjugation deficiency in Escherichia coli $\mathrm{K}$ 12. FEBS Letters 223, 387-390.

RoBerts, M. \& FALKow, S. (1977). Conjugal transfer of $\mathbf{R}$ plasmids in Neisseria gonorrhoeae. Nature, London 266, 630-631.

SChNeIDER, H., HAle, T. L., Zollinger, W. D., SEID, R. C., JR, HAMmaCK, C. A. \& GRIFFISS, J. M. (1984). Heterogeneity of molecular size and antigenic expression within lipooligosaccharides of individual strains of Neisseria gonorrhoeae and Neisseria meningitidis. Infection and Immunity 45, 544-549. 
Schweizer, M. \& HenNing, U. (1977). Action of a major outer cell envelope membrane protein in conjugation of Escherichia coli K-12. Journal of Bacteriology 129, 1651-1652.

SteIN, R. \& HeATH, E. C. (1979). Incorporation of Nacetylglucosamine into the core region of the cell wall lipopolysaccharide of Escherichia coli. Journal of Biological Chemistry 254, 4101-4109.
TSAI, C. M. \& Frasch, C. E. (1982). A sensitive silver stain for detecting lipopolysaccharides in polyacrylamide gels. Analytical Biochemistry 119, 115-119.

WestPhal, O. \& JANN, K. (1965). Bacterial lipopolysaccharides; extraction with phenol-water and further applications of the procedure. Methods in Carbohydrate Chemistry 5, 83-91. 